\title{
Diagnostic Test of Platelet Lymphocyte Ratio for Screening of Complex Coronary Lesion in Different Age Group of Acute Coronary Syndrome
}

\author{
Irma Wahyuni*, Sally Aman Nasution², Ika Prasetya Wijaya², Lugyanti Sukrisman ${ }^{3}$ and Cleopas Martin Rumende $^{4}$
}

${ }^{1}$ Faculty of Medicine, Department of Internal Medicine, Universitas Indonesia-Cipto Mangunkusumo Hospital, Indonesia

${ }^{2}$ Faculty of Medicine, Division of Cardiology, Department of Internal Medicine, Universitas Indonesia-Cipto Mangunkusumo Hospital, Indonesia

${ }^{3}$ Faculty of Medicine, Division of Medical Hematology and Oncology, Department of Internal Medicine, Universitas Indonesia-Cipto Mangunkusumo Hospital, Indonesia

${ }^{4}$ Faculty of Medicine, Division of Pulmonology, Department of Internal Medicine, Universitas Indonesia-Cipto Mangunkusumo Hospital, Indonesia

\begin{abstract}
Background: Increasing of ACS case with complex coronary lesion and in increase needs of CABG, we need tools to help in stratification of high risk patient that can be used in daily clinical practice, and even can be used in first line of health care facilities in Indonesia. By doing early stratification of high risk patient, hopefully it can decrease the morbidity and mortality in ACS cases.
\end{abstract}

Aim: Evaluate diagnostic accuracy of PLR in identifying a complex coronary lesion and optimal cut-off point of PLR between $\leq 45$ years old group and $>45$ years old group subjects.

Method: This is a cross sectional study which was conducted retrospectively in ACS patients from January 2012 until July 2015. The inclusion criteria are adult ACS patients (age $\geq 18$ years old) diagnosed with ACS and who underwent coronary angiography during hospitalization. The diagnostic accuracy was determined by calculating the sensitivity, specificity, Positive Likelihood Ratio (LR+), and Negative Likelihood Ratio (LR-). The cut-off point was determined using ROC curve.

Results: The proportion of complex coronary lesion in this study was $47.2 \%$. The optimal cut-off point in $\leq$ 45 year's old group was 111.06 with sensitivity, specificity, LR+, and LR- respectively $91.3 \%, 91.9 \%, 11.27$ and 0.09 . The optimal cut-off points in $>45$ years old groups was 104,78 with sensitivity, specificity, LR+, and LRrespectively $91.7 \%, 58.6 \%, 2.21$ and 0.14 .

Conclusion: The optimal cut-off point of $\leq 45$ years old groups is 111.06 and for $>45$ years old group is 104.78 with AUC $93.9 \%(p<0.001) 77.3 \%(p<0.001)$, respectively.

Keywords: PLR; Complex coronary lesion; Gensini score; ACS

\section{Introduction}

Cardiovascular disease was $5^{\text {th }}$ causes of death worldwide, both in developed country or developing country. About $80-90 \%$ deaths in cardiovascular disease was due to coronary artery disease (CAD) [1,2]. From RISKESDAS, a national research program in 2013, the prevalence of CAD increasing from $0.9 \%$ in 2007 to $1.5 \%$ [3]. This prevalence also increasing respectively with age of the patients. Acute coronary syndrome (ACS) causing high rate hospitalization and mortality. In Indonesia there are 1009 cases admitted to intensive coronary care unit (ICCU) Dr. Cipto Mangunkusumo National Referral Hospital within 3 years with mortality rate $17.5 \%$ on 2010 [4].

Acute coronary syndrome increase risk of death through various mechanisms that somehow related to complexity of lesion involved. From preliminary study in 2015, there is increasing need for performing early Percutaneous Coronary Intervention (PCI) each year, and there for also increasing needs for Coronary Artery Bypass Graft (CABG). Thus condition shows that there are more complex lesion patient was admitted to the ICCU unit [5]. Age as the unmodifiable factor in ACS, that have increased incidence of it in age $>45$ years old in man and $>$ 55 years old in woman [6]. Trip et al. [7] said that there is increasing incidence of death in age $>60$ years old (28.9\% RR 1.5). The incidence of ACS in young adults is lesser, but it seems like increasing lately. In Indonesia several studies shows that there are high proportion of young adults with ACS compare to previous study [8-11]. Spectrum of the ACS itself was changing in young adults from UAP to STEMI.

The role of inflammation in predicting bad outcome in ACS patient was known before; it is related to more complex lesion, increasing mortality risk and major adverse cardiac event (MACE) [12-14]. Inflammatory that has been investigated is less applicable due to lack of funding. As an alternative, platelet lymphocyte ratio (PLR) was more accessible and can describe inflammatory process, and in can be used in cardiovascular cases [15]. The changes of platelets and lymphocyte during acute stress give a simple picture of the inflammatory process involved. This is an easy and applicable tool of examination in clinical practice as an inflammatory marker that give an prognostic value on cardiovascular patient [16-20]. Thus increasing of the complexity of the lesion also related to high risk of MACE [21].

Last several years there are increasing in PCI needs and stratification of the patient who needs it was crucial. It is not only determined by the clinical condition of the patient, but PLR also can be used to help in the decision making. PLR value in Indonesia not similar to other countries due to different geographically, different individual and genetic characteristic, habits, and chronic infection pattern. The role of inflammation in each age group is also different. As explain before,

*Corresponding author: Dr. Irma Wahyuni, Faculty of Medicine, Department of Internal Medicine, Universitas Indonesia-Cipto Mangunkusumo Hospital Indonesia, Tel: +6281320391001; E-mail: irma_dr@yahoo.com

Received April 17, 2018; Accepted August 04, 2018; Published August 09, 2018

Citation: Wahyuni I, Nasution SA, Wijaya IP, Sukrisman L, Rumende CM (2018) Diagnostic Test of Platelet Lymphocyte Ratio for Screening of Complex Coronary Lesion in Different Age Group of Acute Coronary Syndrome. J Cardiovasc Dis Diagn 6: 335. doi: 10.4172/2329-9517.1000335

Copyright: @ 2018 Wahyuni I, et al. This is an open-access article distributed under the terms of the Creative Commons Attribution License, which permits unrestricted use, distribution, and reproduction in any medium, provided the original author and source are credited. 
there for we can conclude that PLR potential for indentified whether an ACS patient having a complex coronary lesion or not. Previous study $[16,18-21]$ only use one cut-off point in all ages, but since there are changing of the ACS spectrum in young adults, there for need a further evaluation for accuracy of using PLR and find the optimal cut-off point that can be used in daily practice.

\section{Research Methodology}

The design of our study was a cross sectional diagnostic study that using secondary data from medical records in ICCU Dr. Cipto Mangunkusumo Hospital from 2012 - 2015. Data was collected in end of 2015 and by total population sampling. Inclusion was, (1) Age $>18$, (2) ACS patient whose undergo PCI during admission. The exclusion criteria including, (1) Incomplete data of leukocyte, platelets, differential count of leukocyte, urinalysis, chest $\mathrm{x}$-ray, and angiography data, (2) onset less than 1 hour and more than 48 hours, (3) hematology abnormalities : aplastic anemia, leukemia, thrombocytopenia (platelets $<150.000 / \mathrm{mm}^{3}$ ), polycythemia Vera, (4) malignancy or autoimmune diseases : systemic lupus erythematous (SLE), Idiopathic thrombocytopenia purpura (ITP), Autoimmune Hemolytic Anemia (AIHA), rheumatoid arthritis, and scleroderma with or without steroids, (5) Using systemic steroids, (6) Active infection, tuberculosis, sepsis, chronic infection such as HBV, HCV, and HIV, (7) history of CABG.

$$
P L R=\frac{\text { platelet }\left(\mathrm{sel} / \mathrm{mm}^{3}\right)}{\text { absolut lymphocyte }}
$$

Data analysis was performed using SPSS version 21.0. The PLR was calculate by equation value that compared to Gensini score 22.23 was presented in Area under Curve (AUC) based on Receiver operating characteristic (ROC) and cut-off points. The results than explains in sensitivity (Se), specificity (Sp), positive predictive value (PPV), and negative predictive value (NPV). This study has been approved by the Ethical Committee, Faculty of Medicine, University of Indonesia, by the registration number $921 / \mathrm{UN} 2 . \mathrm{F} 1 / \mathrm{ETIK} / 2015$ on October, $19^{\text {th }}$ 2015.

\section{Results}

During the study, there are 996 patient with ACS admitted to ICCU unit. About 871 patient was excluded from the study due to infection (274), malignancy (98), autoimmune and hematology abnormalities (99), the incorrect onset of illness (154) and history of CABG (46). Total patient who submitted to the study was 125 patients.

From 125 subject of the study, the proportion of complex coronary lesion with Gensini score $(>53)$ was $47.2 \%$ and Gensini score $(\leq 53)$ was $52.8 \%$. The characteristic of the subject was explained in next table. From the study there are $48 \%$ patients was $\leq 45$ years old and $52 \%$ was above 45 years old. In $\leq 45$ years old group there are $38.3 \%$ patient having high Gensini score, whereas there are $55.4 \%$ of high Gensini score found in $>45$ years old group (Table 1 ).

The mean of PLR of high Gensini score on both group was different, there are higher PLR mean in younger age group $171.08 \pm$ 83.54 compared to older groups $209.91 \pm 164.45$.

Using ROC curve we calculate the PLR cut-off point that can be used in predicting complex coronary lesion or high Gensini score of ACS patient in $\leq 45$ year's old group. Based on ROC, the AUC was 93.3\% (CI 95\% 87.4 - 100) with p-value $<0.001$ (Figure 1). There are 60 cut-off points with their each sensitivity and specificity. The optimal

\begin{tabular}{|c|c|c|c|c|}
\hline \multirow[b]{2}{*}{ Characteristics } & \multicolumn{2}{|c|}{$\leq 45$ years old $(n=60)$} & \multicolumn{2}{|c|}{$>45$ years old $(n=65)$} \\
\hline & $\begin{array}{l}\text { Gensini }>53 \\
(n=23)\end{array}$ & $\begin{array}{l}\text { Gensini } \leq 53 \\
(n=37)\end{array}$ & $\begin{array}{l}\text { Gensini }>53 \\
(n=36)\end{array}$ & $\begin{array}{l}\text { Gensini } \leq 53 \\
(n=29)\end{array}$ \\
\hline \multicolumn{5}{|l|}{ Gender, n (\%) } \\
\hline Male & $20(87)$ & $22(59.5)$ & $28(77.8)$ & $21(72.4)$ \\
\hline Females & $3(13)$ & $15(40.5)$ & $8(22.2)$ & $8(27.6)$ \\
\hline Age, mean (SD) & $42 \pm 3$ & $42 \pm 3$ & $62 \pm 8$ & $62 \pm 9$ \\
\hline IMT, mean (SD) & $26.1 \pm 3.9$ & $26.0 \pm 3.5$ & $24.7 \pm 2.7$ & $24.7 \pm 4.1$ \\
\hline \multicolumn{5}{|l|}{ ACS type, n (\%) } \\
\hline STEMI & $14(60.9)$ & $11(29.7)$ & $18(50.0)$ & $10(34.5)$ \\
\hline NSTEMI & $3(13.0)$ & $8(21.6)$ & $12(33.3)$ & $3(10.3)$ \\
\hline UAP & $6(26.1)$ & $18(48.6)$ & $6(16.7)$ & $16(55.2)$ \\
\hline PLR, mean (SD) & $171.08 \pm 83.54$ & $88.51 \pm 24.28$ & $209.91 \pm 164.45$ & $133.01 \pm 108.22$ \\
\hline Platelets, median (range) & $\begin{array}{l}225.000 \\
(102.000-659.000)\end{array}$ & $\begin{array}{l}290.000 \\
(109.000-1.148 .000)\end{array}$ & $\begin{array}{l}262.500 \\
(147.000-736.000)\end{array}$ & $\begin{array}{l}242.000 \\
(124.000-330.000)\end{array}$ \\
\hline Absolut lymphocyte, mean (SD) & $2369.6 \pm 1241.7$ & $2488.5 \pm 1115.2$ & $1982.1 \pm 1270.9$ & $1900.8 \pm 1083.9$ \\
\hline Gensini score, mean (SD) & $169.3 \pm 74.1$ & $18.9 \pm 16.9$ & $161.0 \pm 72.7$ & $25.0 \pm 17.9$ \\
\hline \multicolumn{5}{|l|}{ Comorbidities, n (\%) } \\
\hline $\mathrm{DM}$ & $7(30.4)$ & $12(32.4)$ & $14(38.9)$ & $4(13.8)$ \\
\hline Hypertension & $13(56.5)$ & $9(24.3)$ & $23(63.9)$ & $16(55.2)$ \\
\hline Dyslipidemia & $18(78.3)$ & $29(78.4)$ & $25(69.4)$ & $23(79.3)$ \\
\hline Family History of CHD & $5(21.7)$ & $5(13.5)$ & $9(25.0)$ & $13(44.8)$ \\
\hline Smoking. n (\%) & $10(43.5)$ & $7(18.9)$ & $13(36.1)$ & $9(31.0)$ \\
\hline LDL, median (range) & $113(50-335)$ & $114(48-165)$ & $116.19 \pm 38.44$ & $107.79 \pm 36.16$ \\
\hline HDL, median (range) & $40(15-59)$ & $37(15-64)$ & $41(22-70)$ & $39(11-72)$ \\
\hline Total cholesterol. median (range) & $188(114-446)$ & $174(58-264)$ & $178.5 \pm 44.82$ & $164.59 \pm 39.21$ \\
\hline Trygliserida, median (range) & $140(56-313)$ & $146(58-383)$ & $106(52-390)$ & $128(43-353)$ \\
\hline Uric Acid, mean (SD) & $7.9 \pm 2.3$ & $6.9 \pm 3.0$ & $8.1 \pm 1.9$ & $7.1 \pm 2.9$ \\
\hline LFG, mean (SD) & $82.3 \pm 27.2$ & $72.6 \pm 36.2$ & $56.1 \pm 23.3$ & $63.1 \pm 23.4$ \\
\hline
\end{tabular}

Table 1: Study subject characteristic based on age group. 

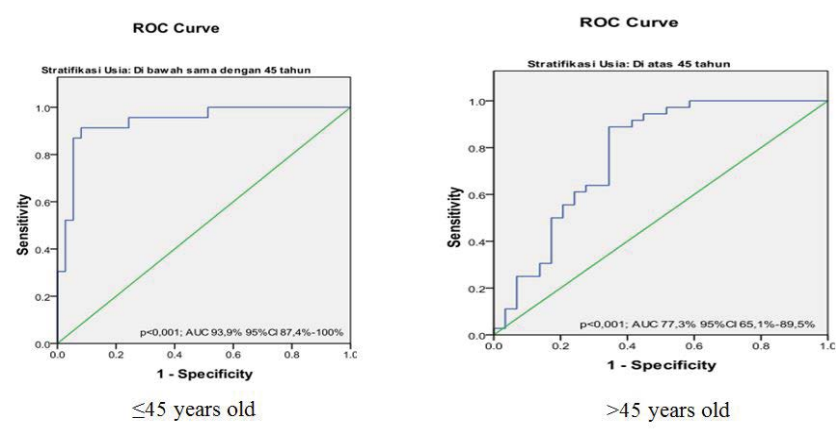

Figure 1: ROC curve and PLR cut-off point based on age groups.

\begin{tabular}{|c|c|c|c|c|c|c|c|}
\hline $\begin{array}{l}\text { Age } \\
\text { group }\end{array}$ & $\begin{array}{l}\text { PLR } \\
\text { cut off } \\
\text { point }\end{array}$ & $\begin{array}{l}\text { Sn, \% } \\
(95 \% \text { Cl) }\end{array}$ & \begin{tabular}{|l} 
Sp, \% \\
$(95 \%$ Cl)
\end{tabular} & $\begin{array}{l}\text { PPV, \% } \\
(95 \% \\
\text { Cl) }\end{array}$ & \begin{tabular}{|l|} 
NPV \\
$\%(95 \%$ \\
Cl)
\end{tabular} & $\begin{array}{l}\text { Pos } \\
\text { Likelihood } \\
\text { ratio, } \\
(95 \% \text { Cl) }\end{array}$ & $\begin{array}{l}\text { Neg. } \\
\text { Likelihood } \\
\text { ratio } \\
(95 \% \mathrm{Cl})\end{array}$ \\
\hline$\leq 45$ & 111.06 & $\begin{array}{c}91.3 \\
(71.96- \\
98.9)\end{array}$ & $\begin{array}{l}91.9 \\
(78.1- \\
98.3)\end{array}$ & $\begin{array}{c}87.5 \\
(67.7- \\
97.4)\end{array}$ & $\begin{array}{c}94.4 \\
(81.3- \\
99.3)\end{array}$ & $\begin{array}{l}11.27 \\
(3.8- \\
33.6)\end{array}$ & $\begin{array}{c}0.09 \\
(0.03- \\
0.36)\end{array}$ \\
\hline$>45$ & 104.78 & $\begin{array}{c}91.7 \\
(77.5- \\
98.3)\end{array}$ & $\begin{array}{c}58.6 \\
(38.9- \\
76.5)\end{array}$ & $\begin{array}{c}73.3 \\
(58.1- \\
85.4)\end{array}$ & $\begin{array}{c}85 \\
(62.1- \\
96.8)\end{array}$ & $\begin{array}{l}2.21 \\
(1.42- \\
3.45)\end{array}$ & $\begin{array}{c}0.14 \\
(0.05- \\
0.44)\end{array}$ \\
\hline
\end{tabular}

Table 2: Comparison of PLR ratio between age groups based on ROC curve.

cut-off point was found in 37th data which are 111.06 with $91.3 \%$ sensitive, $91.9 \%$ specific, PPV 87.5\%, NPV 94.4\%, positive LR 11.27 , and negative LR 0.09. According to the result the accuracy of 111.06 is good and can be used as optimal cut-off point in this age group (Figure 1).

Based on ROC curve on $>45$ years old age group, the AUC of PLR was $77.3 \%$ (CI 65,1, 1 - 89,5) with p-value $<0.001$ (Figure 1) From 65 cut-off point, the optimal cut-off point in this group was 104.78. Respectively the sensitivity, specificity, PPV, NPV, positive LR, and negative LR are $91.7 \%, 58.6 \%, 73.3 \%, 85 \%, 2.21$ and 0.14 . Result data shown in Table 2.

\section{Discussion}

From this study, there are 125 subjects consist of $72.8 \%$ males and $27.2 \%$ females. The data is similar with previous study, where there are high incidence of ACS founds in male patient rather than females [1]. The median age of subjects was 48 years old, with the youngest was 33 years old and the oldest was 80 years old. This characteristic is different from the previous theory where is state that the ACS incidence is increase in patient $>45$ years old (male) or $>55$ years old (females), in this study event of ACS happen as youngest as 33 years old. From the study there are quite different of age related complex lesion was found, which is differ from previous study that state no significant relation between age and complex lesion [22-26].

The study also shows that proportion of ACS in age $<45$ years old as much as $48 \%$, and it is higher than other descriptive study that performed in Indonesia, which is $22,2 \%$ in Cipto Mangunkusumo Hospitals during 2008 - 2012 and 13,5\% in Sardjito Hospital in 2014 [10-11]. This proportion also higher than other ACS in young adult in general population $(2-10 \%)$ [8]. The data might be due to exclusion criteria that exclude infection since infection usually found as comorbid on older patient with ACS. The shifting of onset of the illness maybe due to shifting of risk factor of ACS in Indonesia. It state in latest RISKESDAS that there are shifting of CAD risk factor such as smoking, sedentary life style, and obesity which the biggest proportion was found in ages $30-50$ years old [8,27-30]. This is different from the previous data which that risk factor was seen highest in age $>45$ [24] The shifting of CAD risk factor also shifts the age of ACS onset on the population. There for should increase our awareness.

Median PLR in high Gensini group was higher (146.54 vs. 89.57), this supporting the pathophysiology of ACS that states inflammatory burden related to complexity of the lesion. Several previous studies shows that there are relation between increasing of PLR to the complex coronary lesion, but those studies using tools that not quite represent the coronary lesion complexity. In the other hands, the cutoff point that found was different in each study, that shows different region might be influenced by different inflammatory burden. Those differences make it difficult on using in to clinical practice in our region [24,25,27].

ST elevation myocardial infarction (STEMI) in this study was higher in high Gensini group (54.2\% vs. $31.8 \%)$. Overall the STEMI incidence in this study was higher than other type of ACS, which is $42.4 \%$. On younger group, STEMI was found dominate with rate $60.9 \%$ compare to UAP (26.1\%). Changes of the ACS spectrum in younger group were noted by the writer. The data supports previous related study regarding young adult ACS says that there are changing of ACS spectrum from UAP to STEMI in this group of age [28-30]. The data from this study also different from the previous data in ICCU unit from 2008 - 2012 where UAP still higher than STEMI/NSTEMI in young patient group [11]. This condition shows that there is worsening of the stenosis in young adult, where in previous condition in this group was higher due to vasospasm related ischemia.

On the study result shows AUC of PLR in high Gensini group in young ACS patient group was 93.3\% (CI 95\%, 87 - 100, p-value $<0,001$ ). There are 60 cut off points from this group, with optimal PLR cut off point on $\leq 45$ years old group was 111.06. Consecutively the sensitivity, specificity, PPV, NPV, positive LR and negative LR was $91.9 \%, 87.5 \%$, $94.4 \%, 11.27$ and 0.09 . This cut off can be used as screening for complex coronary lesion in younger group of due to high of specificity. The pretest probability if this study is $38.3 \%$ and the post-test probability (for positive result) was $87.3 \%$. For example, if a patient $\leq 45$ years old have higher PLR than the cutoff point (111.06), means that the physician can be sure $87.3 \%$ that the patient having a complex coronary lesion.

The cutoff point of PLR in this study in age $>45$ years old was different compare to younger group. The AUC level was $77.3 \%$ (CI $95 \%, 65.1-89.5$, p-value $<0.001$ ). The optimal cut off point out 65 in this study was 104.78 . With consecutively sensitivity, specificity, PPV, NPV, positive LR, and negative LR was $91.7 \%, 58.6 \%, 73.3 \%, 85 \%, 2.21$ and 0.14 . With pre-test probability of this group is $55.3 \%$ and post-test probability (for negative result) was $14.8 \%$, if the patient $>45$ years old with PLR $>104.8$, it is means that physician sure that $14.8 \%$ this patient doesn't have a complex coronary lesion.

The recommendation of using PLR as screening of complex coronary lesion in ACS patient can be used in daily practice, especially in order to make a stratification of the severity of the patient beside the clinical condition. These tools can be used in stratification on elective procedure as well.

\section{Limitation of the Study}

This is a retrospective cross sectional study. It might limit the information and the similarity of anamnesis technique used. It also might limit the completeness of supporting data related to risk factor such as obesity and others factor that relate to inflammatory status such 
Citation: Wahyuni I, Nasution SA, Wijaya IP, Sukrisman L, Rumende CM (2018) Diagnostic Test of Platelet Lymphocyte Ratio for Screening of Complex Coronary Lesion in Different Age Group of Acute Coronary Syndrome. J Cardiovasc Dis Diagn 6: 335. doi: 10.4172/2329-9517.1000335

as $H$. pylori status because the evaluation does not routinely performed in ICCU unit.

Despite some limitations, this study may provide good evidence to increase physicians' awareness and helping physician to make a good stratification of severity patient with ACS who need undergo intervention treatment.

\section{Conclusion}

Proportion of ACS that has a complex coronary lesion (high Gensini Score) was $47.2 \%$. The optimal cut off point in $\leq 45$ years old group was 111.06 and in $>45$ years old group was 104.78 . The diagnostic accuracy of PLR based on AUC level on both groups is good enough for screening of complex coronary lesion.

\section{References}

1. World Health Organization (2015) Global burden disease, 2014. [cited 2015 July 15]. Available at: http: //apps.who.int/countries/edn/en/en/

2. Indonesian Cardiovascular Specialist Association (2015) Guidelines and management of acute coronary syndromes, 2015.

3. Basic Health Research (2013) Ministry of Health Republic of Indonesia: Basic health research (RISKESDAS), 2013.

4. Setyawan W (2011) TIMI score validation in predicting mortality in acute coronary syndrome patients in Indonesia. University of Indonesia, Jakarta, Indonesia.

5. Kumar B, Zein A, Wahyuni I, Nasution SA (2015) Clinical outcome profile during treatment in patients with acute coronary syndrome in the Intellectual Coronary Care Unit, Cipto Mangunkusumo Hospital, a preliminary study. Department of Internal Medicine, FKUI IPD, Jakarta, Indonesia.

6. Ugur M, Gul M, Bozbay M, Cicek G, Uyarel H, et al. (2014) The relationship between platelet to lymphocyte ratio and the clinical outcomes in ST elevation myocardial infarction underwent primary coronary intervention. Blood Coagul Fibrinolysis 25: 806-811.

7. Trip MD, Cats VM, Van Capelle FJ, Vreeken J (1990) Platelet hyperreactivity and prognosis in survivors of myocardial infarction. N Engl J Med 322: 15491554.

8. Teixeira M, Sa I, Mendes JS, Martins L (2010) Acute coronary syndrome in young adults. Rev Port Cardiol 29: 947-955.

9. Al-Murayeh MA, Al-Masswary AA, Dardir MD, Moselhy MS, Youssef AA (2012) Clinical presentation and short-term outcome of acute coronary syndrome in native young saudi population. J Saudi Heart Assoc 24: 169-175.

10. Setianto BY, Sari J, Hartopo AB, Ra Gharini PP (2014) Acute coronary syndrome in young patients at dr. Sardjito general hospital. Acta Interna 4: 23-28.

11. Isnanta R, Panggabean MM, Alwi I (2014) Comparison of coronary angiography characteristics among acute coronary syndrome patients in young and old age patients at Cipto Mangunkusumo hospital Jakarta. Acta Med Indones 46: 117-123.

12. Furman MI, Benoit SE, Barnard MR, Valeri CR, Borbone ML, et al. (1998) Increased platelet reactivity and circulating monocyte-platelet aggregates in patients with stable coronary artery disease. J Am Coll Cardiol 31: 352-358.

13. Gotsman I, Stabholz A, Planer D, Pugatsch T, Lapidus L, Novikov Y, et al. (2018) Serum cytokine tumor necrosis factor-alpha and interleukin- 6 associated with the severity of coronary artery disease: Indicators of an active inflammatory burden? Isr Med Assoc J. 10: 494-498.
14. Shi Y, Wu Y, Bian C, Zhang W, Yang J, et al. (2010) Predictive value of plasma fibrinogen levels in patients admitted for acute coronary syndrome. Tex Heart Inst J 37: 178-183.

15. Guo C, Zhang S, Zhang J, Liu H, Li P, et al. (2014) Correlation between the severity of coronary artery lesions and levels of estrogen, hs-crp and mmp-9. Exp Ther Med 7: 1177-1180.

16. Azab B, Shah N, Akerman M, McGinn JT (2012) Value of platelet/lymphocyte ratio as a predictor of all-cause mortality after non-st-elevation myocardial infarction. J Thromb Thrombolysis 34: 326-334.

17. Balta S, Ozturk C (2014) The platelet-lymphocyte ratio: A simple, inexpensive and rapid prognostic marker for cardiovascular events. Platelets 26: 680-681.

18. Hudzik B, Szkodzinski J, Gorol J, Niedziela J, Lekston A, et al. (2015) Plateletto-lymphocyte ratio is a marker of poor prognosis in patients with diabetes mellitus and st-elevation myocardial infarction. Biomark Med 9: 199-207.

19. Oylumlu M, Yildiz A, Oylumlu M, Yuksel M, Polat N, et al. ( 2015) Plateletto-lymphocyte ratio is a predictor of in-hospital mortality patients with acute coronary syndrome. Anatol J Cardiol 15: 277-283.

20. Temiz A, Gazi E, Gungor O, Barutcu A, Altun B, et al. (2014) Platelet/ lymphocyte ratio and risk of in-hospital mortality in patients with ST-elevated myocardial infarction. Med Sci Monit 20: 660-665.

21. McDermott MM, Guralnik JM, Corsi A, Albay M, Macchi C, et al. (2005) Patterns of inflammation associated with peripheral arterial disease: The inchianti study. Am Heart J 150: 276-281.

22. Sinning C, Lillpopp L, Applebaum S, Ojeda F, Zeller T, et al. (2013) Angiographic score assessment improves cardiovascular risk prediction: The clinical value of syntax and gensini application. Clin Res Cardiol 102: 495-503.

23. Neeland IJ, Patel RS, Eshtehardi P, Dhawan S, McDaniel MC, et al. (2012) Coronary angiographic scoring systems: An evaluation of their equivalence and validity. Am Heart J 164: 547-552 el.

24. Ayca B, Akin F, Celik O, Yuksel Y, Ozturk D, et al. (2014) Platelet to lymphocyte ratio as a prognostic marker in primary percutaneous coronary intervention. Platelets 26: 638-644.

25. Kurtul A, Murat SN, Yarlioglues M, Duran M, Ergun G, et al. (2014) Association of platelet-to-lymphocyte ratio with severity and complexity of coronary artery disease in patients with acute coronary syndromes. Am J Cardiol 114: 972-978.

26. Sari I, Sunbul M, Mammadov C, Durmus E, Bozbay M, et al. (2015) Relation of neutrophil to lymphocyte and platelet to lymphocyte ratio with coronary artery disease severity in patients undergoing coronary angiography. Kardiol Pol 73 1310-1316.

27. Akboga MK, Canpolat U, Yayla C, Ozcan F, Ozeke O, et al. (2015) Association of platelet to lymphocyte ratio with inflammation and severity of coronary atherosclerosis in patients with stable coronary artery disease. Angiology 67 89-95.

28. Wolk R, Berger P, Lennon RJ, Brilakis ES, Somers VK (2003)Body mass index: A risk factor for unstable angina and myocardial infarction in patients with angiographically confirmed coronary artery disease. Circulation 108: 22062211.

29. Inoue T, Oku K, Kimoto K, Takao M, Nomoto J, et al. (1995) Relationship of cigarette smoking to the severity of coronary and thoracic aortic atherosclerosis. Cardiology 86: 374-379.

30. Tungsubutra W, Tresukosol D, Buddhari W, Boonsom W, Sanguanwang S, et al. (2007) Acute coronary syndrome in young adults: The thai ACS registry. $J$ Med Assoc Thai 90 Suppl 1: 81-90. 